\title{
MerTK is a novel therapeutic target in gastric cancer
}

\author{
Jun Ho Yi ${ }^{1,5, *}$, Jiryeon Jang ${ }^{1, *}$, Jeonghee Cho ${ }^{2, *}$, In-Gu Do ${ }^{3}$, Mineui Hong ${ }^{4}$, Seung Tae Kim ${ }^{1}$, \\ Kyoung-Mee Kim ${ }^{4}$, Sujin Lee ${ }^{1}$, Se Hoon Park ${ }^{1}$, Joon Oh Park ${ }^{1,4}$, Young Suk Park ${ }^{1}$, \\ Won Ki Kang ${ }^{1}$, Ho Yeong Lim ${ }^{1}$ and Jeeyun Lee ${ }^{1}$ \\ ${ }^{1}$ Division of Hematology-Oncology, Department of Medicine, Samsung Medical Center, Sungkyunkwan University School of \\ Medicine, Seoul, Korea \\ ${ }^{2}$ Samsung Genome Institute, Seoul, Korea \\ ${ }^{3}$ Department of Pathology, Kangbuk Samsung Medical Center, Sungkyunkwan University School of Medicine, Seoul, Korea \\ ${ }^{4}$ Department of Pathology and Translational Genomics, Samsung Medical Center, Sungkyunkwan University School of \\ Medicine, Seoul, Korea \\ ${ }^{5}$ Division of Hematology-Oncology, Department of Medicine, Hanyang University Hospital, Seoul, Korea \\ *These authors have contributed equally to this work \\ Correspondence to: Ho Yeong Lim, e-mail: hoylim@skku.edu \\ Jeeyun Lee, e-mail: jyunlee@skku.edu
}

Keywords: gastric cancer, MerTK, patient-derived cells

Received: February 28, $2014 \quad$ Accepted: April 08, $2015 \quad$ Published: April 20, 2015

Copyright: Yi et al. This is an open-access article distributed under the terms of the Creative Commons Attribution License 3.0 (CC BY 3.0), which permits unrestricted use, distribution, and reproduction in any medium, provided the original author and source are credited.

\section{ABSTRACT}

Introduction: The role of MerTK has not been assessed in gastric cancer (GC). The aim of this study was to identify a subgroup of GC patients with MerTK tumor overexpression, and to evaluate MerTK as a potential therapeutic target in this disease.

Methods: Protein and mRNA expression of MerTK were evaluated, and other various in vitro analyses including shRNA transfection, cell cycle anslysis, MTS assay and colony forming assay were carried out with GC cell lines and GC patient-derived cells (PDCs).

Results: shRNA-mediated knockdown of MerTK resulted in inhibition of cell growth, as well as increased cellular apoptosis in MerTK positive GC cells. Out of 192 GC patients, $16(8.3 \%)$ patients showed strong protein expression and they had a significantly shorter overall survival compared to those with no MerTK expression. In 54 cases of GC PDCs, 4 cases (7.4\%) showed mRNA overexpression, which was comparable to the protein expression rate. When we administered UNC1062, a novel MerTK-selective small molecular tyrosine kinase inhibitor, proliferation of MerTK overexpressing GC cells and PDCs were considerably inhibited.

Conclusion: MerTK may be involved in GC carcinogenesis, and it could be a potential novel therapeutic target in GC patients.

\section{INTRODUCTION}

Gastric cancer (GC) is one of the most lethal malignancies worldwide, with an incidence of 18.9/100, 000 cases per year and a mortality rate of $14.7 / 100,000$ per year [1]. While complete surgical resection is the primary treatment for potential cure, approximately $50 \%$ of the patients eventually have unresectable or metastatic disease [2,3]. Although chemotherapy significantly improved survival in comparison to best supportive care in these patients [4], the benefits of cytotoxic agents are limited to just over 1 year $[5,6]$. After molecular targeted agents have been introduced for treatment of GC, trastuzumab which targets HER-2 (human epidermal receptor-2), and ramucirumab which targets VEGFR-2 (vascular endothelial growth factor receptor-2) proved their clinical efficacies in large clinical trials [7-9]. Despite of these successes, the pathogenesis of GC is poorly understood, and there are still unmet needs for the novel therapy. 
A number of receptor tyrosine kinases (RTKs) are implicated in the pathogenesis of cancer, and among them, aberrant activation of the TAM (Tyro-3, Axl, and MerTK) family of RTKs is known to be associated with pathogenesis of several malignancies, including melanoma $[10,11]$, leukemia [12-14], and glioma $[15,16]$. They share structural similarity with a combination of 2 immunoglobin-like domains and dual fibronectin type III repeats in the extracellular region and a cytoplasmic kinase domain, and are involved in innate immune response [17], angiogenesis [18] and regulating nervous systems [19]. While several point mutations have been reported, most cases of abnormal receptor activation identified in tumors probably resulted from abnormal expression of either TAM kinases or their ligands, growth arrest specific gene 6 (Gas6) [20]. Although the detailed molecular mechanism underlying TAM RTKs-driven carcinogenesis remains unclear, previous in vivo and in vitro studies have suggested that activated anti-apoptotic pathways mediated by PI3K and MAPK via the TAM RTKs may play a crucial role in this mechanism.

Whilst several studies have suggested potential carcinogenic role of Axl overexpression in solid tumors [21-23], the role of MerTK has yet been understood, especially patients with GC. In the current study, we have found that shRNA-mediated knockdown in MerTK(+) GC cells led to a considerable growth inhibition and apoptosis. In addition, we reviewed surgical specimens of 192 GC patients and found that a subset of these patients has MerTK protein overexpression, and that this in turn is significantly association with a poor clinical outcome. Furthermore, we examined the efficacy of UNC1062, a novel MerTKspecific small molecule, in MerTK $(+)$ GC cell lines and patient derived cells (PDCs) from MerTK overexpressing GC. Taken together, our data suggest that MerTK may be involved in carcinogenesis of $\mathrm{GC}$, and could be a potential target for drug development in a subset of GC patients.

\section{RESULTS}

\section{GC cell line screening for MerTK overexpression}

To investigate the functional role of overexpressed MerTK in GC, we sought cell lines expressing high levels of MerTK by screening 17 GC cell lines by using RTPCR and western blot (Figure 1A). Based on these data, we selected HSC-60 and SNU-5 as MerTK-positive cell lines, and SNU-668 cells as a MerTK-negative cell line, for further experiments.

\section{Knockdown of MerTK causes cell death via inducing apoptosis}

Next, by lentiviral infection, we introduced three vectors encoding shRNAs (M862, M864, and M865) targeting the sequences of MerTK into HSC-60 and SNU668 cells along with a control shRNA targeting GFP. Compared to the control shRNA, we found that 2 shRNAs (shM864 and M865) reduced the expression levels of MerTK mRNA as well as MerTK protein in HSC-60 cells by more than $80 \%$ as determined by quantitative RT-PCR and western blot analysis, respectively, confirming the specific ablation of MerTK (Figure 1B). The growth of HSC-60 cells was significantly inhibited by both the M864 and M865 clones compared to that of control shRNAtreated colony $(P<0.001)$. A similar effect on growth was observed for another MerTK-positive cell line, SNU-5. As a control, we transfected the non-MerTK expressing SNU668 cells with the M864 and M865 clones, but this had no effect on cell growth (Figure 1C).

We next examined whether knockdown of MerTK affects the cell cycle. Transfection with M864 or M865 significantly increased the sub-G1 fraction, that is, the fraction of apoptotic cells, compared to the control (M862) clone. $(16.3 \%, 12.5 \%$, and $4.1 \%$ in cells transfected with M864, M865, and M862, respectively; Figure 1D). In contrast, there was no significant increase in the sub-G1 fraction of M862-, M864-, or M865-transfected SNU668 cells. Collectively, these results suggest that MerTK plays an important role in cell growth as well as cell cycle progression in a subset of GC cell lines that overexpresses MerTK.

\section{MerTK protein overexpression predicted poor prognosis in GC}

To examine the role of MerTK in patients with $\mathrm{GC}$, we performed a retrospective analysis of $192 \mathrm{GC}$ patients. The baseline characteristics are described in Table 1. MerTK overexpression (characterized as IHC intensity $2-3$ ) was present in 16 patients $(8.3 \%)$, and weak expression (intensity 1) was identified in 11 patients $(5.7 \%)$. Representative sections showing MerTK overexpression are shown in Figure 2. Regarding the mRNA expression, 4 of 54 cases (7.4\%) of GCderived PDCs demonstrated MerTK overexpression by the NanoString-based multigene assay. Notably, of the 4 cases for which MerTK mRNA overexpression was identified, all of the primary tumors were characterized by IHC to have strong MerTK overexpression (data not shown).

With the median follow-up duration of 107.6 months (95\% confidence interval (CI) 100.5 - 114.7 months), MerTK overexpressed GCs were associated with a significantly shorter OS (median OS, 34.4 months, 95\% CI, 8.6 - 66.9 months) when compared to those without MerTK overexpression (median OS not reached, $p=$ 0.007) (Figure 3). For further characterization of MerTKpositive GC patients, we performed subset analysis. The patients with MerTK overexpression were more likely to have intestinal-type tumors $(81.3 \%$ vs. $27.8 \%, p<0.0001)$, 
A
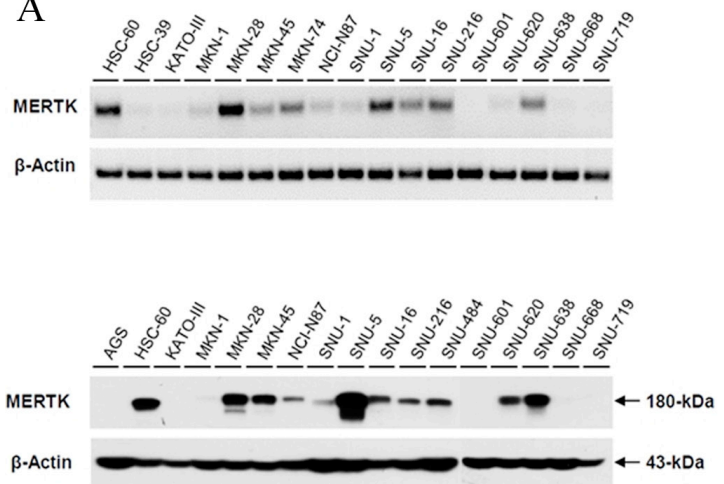

B
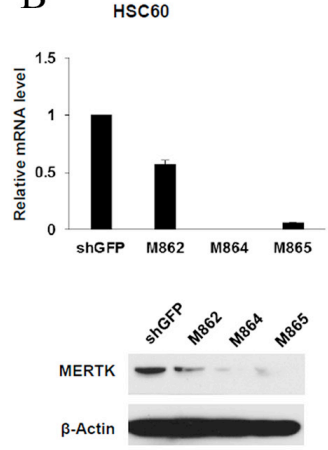

D

SNU-5
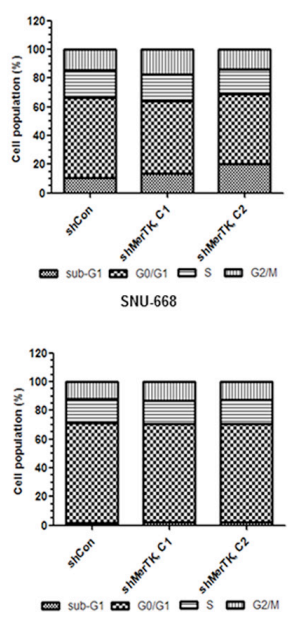

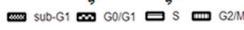

SNU-668
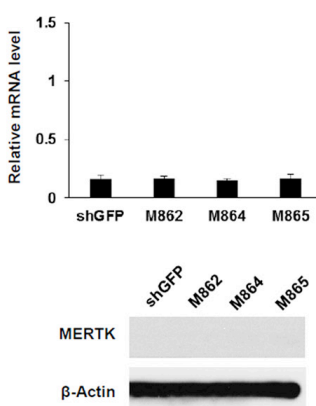

HSC.60

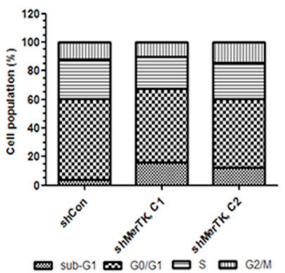

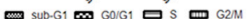
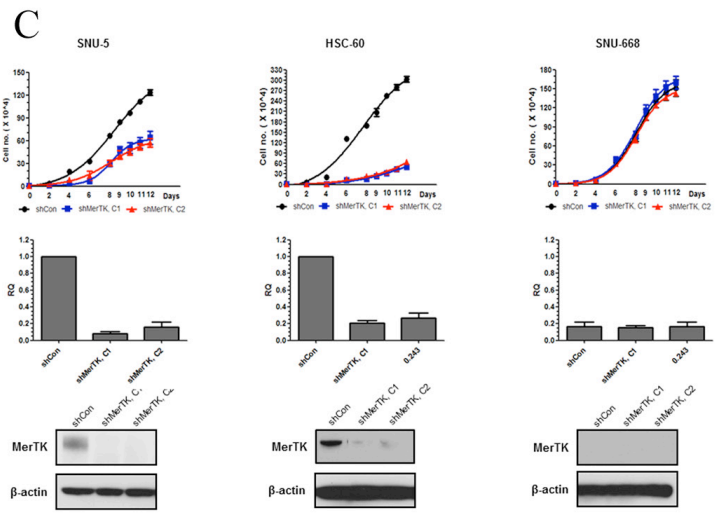

Figure 1: A. Screening for MerTK positive GC cell lines. (Upper, RT PCR; lower, western blot) B. In HSC-60 (MerTKoverexpressing) cells, shRNA (M864, M865)-mediated knockdown resulted in decreased expression of MerTK mRNA and protein. In SNU-668 cells (MerTK negative), neither the level of mRNA nor protein changed after lentiviral infection. C. The proliferation of two MerTK-positive cell lines (SNU-5 and HSC-60) was significantly inhibited by MerTK targeting shRNA, whereas proliferation of SNU688 was not affected D. Transfection with MerTK-specific shRNA significantly increased the apoptotic fraction of SNU-5 and HSC-60 cells, compared to a control (M862) clone (16.3\%, 12.5\%, and 4.1\% in cells transfected with M864, M865, and M862, respectively). The apoptotic fraction of SNU-668 cells was unchanged.

and advanced stage tumors $(68.8 \%$ vs. $41.5 \%, p=0.036$ Table 2). Multivariate analysis revealed that MerTK overexpression was associated with poor OS (hazard ratio [HR] 5.50, 95\% CI $2.41-12.59, p<0.001)$, along with advanced-stage tumors, (HR 2.79, 95\% CI $1.61-4.85$, $p<0.001$ ), and diffuse-type tumors (HR 2.29, 95\% CI $1.16-4.50, p=0.017$; Table 2).

\section{Effects of UNC1062 on GC cells}

To evaluate effects of UNC1062, a novel MerTKspecific small molecular TKI, on GC cells, we performed a cell viability assay using commercial GC cell lines and PDCs with MerTK mRNA overexpression, as identified by the nCounter assay. The MerTK-positive PDCs showed similar sensitivity to UNC1062 and IC50 values similar to those of HSC-60 (Figure 4A). And to characterize the functional consequences of MERTK-mediated prosurvival signaling, we carried out colony forming assay
(Figure 4B). The vehicle untreated SNU-668, HSC-60, and PDCs formed $30.00 \pm 0.333,53.00 \pm 0.333$, and $41.00 \pm 0.8819$ colonies, respectively. When UNC1062 was administered, SNU-668 cells formed an average of $21.00 \pm 0.333$ colonies while colony formation of both HSC-60 and the PDCs was abolished. By western blot, we observed that inhibition of the MerTK pathway by UNC1062 resulted in the inhibition of downstream phosphorylation of AKT and ERK1/2 (Figure 4C). Again, we observed a similar pattern between PDCs and HSC-60.

\section{DISCUSSION}

In the current study, we have found that 1) MerTKspecific shRNA knockdown resulted in considerable growth inhibition and inducing apoptosis in MerTKoverexpressing GC cell lines; 2) MerTK protein overexpression by IHC was found in $8.3 \%(16 / 192)$ of 
TABLE 1: Baseline characteristics of the MerTK-IHC cohort $(n=192)$

\begin{tabular}{|c|c|}
\hline & $N(\%)$ \\
\hline Age, median (range) & $51(28-74)$ \\
\hline \multicolumn{2}{|l|}{ Sex } \\
\hline Male & $120(62.5)$ \\
\hline Female & $72(37.5)$ \\
\hline \multicolumn{2}{|l|}{ Type of gastrectomy } \\
\hline Subtotal gastrectomy & $131(68.2)$ \\
\hline Total gastrectomy & $61(31.8)$ \\
\hline \multicolumn{2}{|l|}{ WHO Histologic classification } \\
\hline Well to moderately differentiated & $51(26.6)$ \\
\hline Poorly differentiated & $79(41.1)$ \\
\hline Signet ring cell & $56(29.2)$ \\
\hline Mucinous & $5(2.6)$ \\
\hline Others & $1(0.5)$ \\
\hline \multicolumn{2}{|l|}{ Lauren's classification } \\
\hline Intestinal-type & $62(32.3)$ \\
\hline Diffuse-type & $123(64.1)$ \\
\hline Mixed-type/Unknown & $7(3.6)$ \\
\hline \multicolumn{2}{|l|}{ Lymphovascular invasion } \\
\hline Present/identified & $93(48.4)$ \\
\hline Not present/Not identified & $99(51.6)$ \\
\hline \multicolumn{2}{|l|}{ Pathologic stage* } \\
\hline IB & $32(16.7)$ \\
\hline II & $76(39.6)$ \\
\hline IIIA & $50(26.0)$ \\
\hline IIIB & $8(4.2)$ \\
\hline IV & $26(13.5)$ \\
\hline
\end{tabular}

*According to AJCC 6th edition

GC patients, who were associated with a poor survival duration; 3) MerTK mRNA overexpression was found in $7.4 \%(4 / 54)$ cases of GC PDCs, which was comparable with the MerTK protein overexpression; and 4) UNC1062 inhibited tumor growth of MerTK-overexpressing cell lines and PDCs. Importantly, these effects specifically occurred in a cell line expressing high levels of MerTK, suggesting that targeting MerTK could be a novel therapeutic option in MerTK overexpressing GC.

Despite of recent advances of early screening methods and treatments, GC still remains as one of the deadliest disease. Even after extended surgical resection followed by proper adjuvant treatment, over $30 \%$ of patients will experience disease recurrence or cancer-related death
$[3,25]$. Regarding the genomic profiles of GC patients, two large-scaled whole-exome sequencing studies have shown that only two genes are found as commonly mutated between two studies [26, 27], pointing the heterogeneity of the disease. And using various genomic analytic tools, a study by Deng et al. has found that at least $37 \%$ of GC patients may be treated by RTK directed therapies [28]. These findings necessitate precise approaches in treatment of GC patients.

After first identified in leukemic lymphocytes [29], the function of MerTK has been steadily investigated. While several somatic mutations of MerTK were found in certain cancers [30], it is believed that their functional role is limited, and ectopic expression or overexpression 

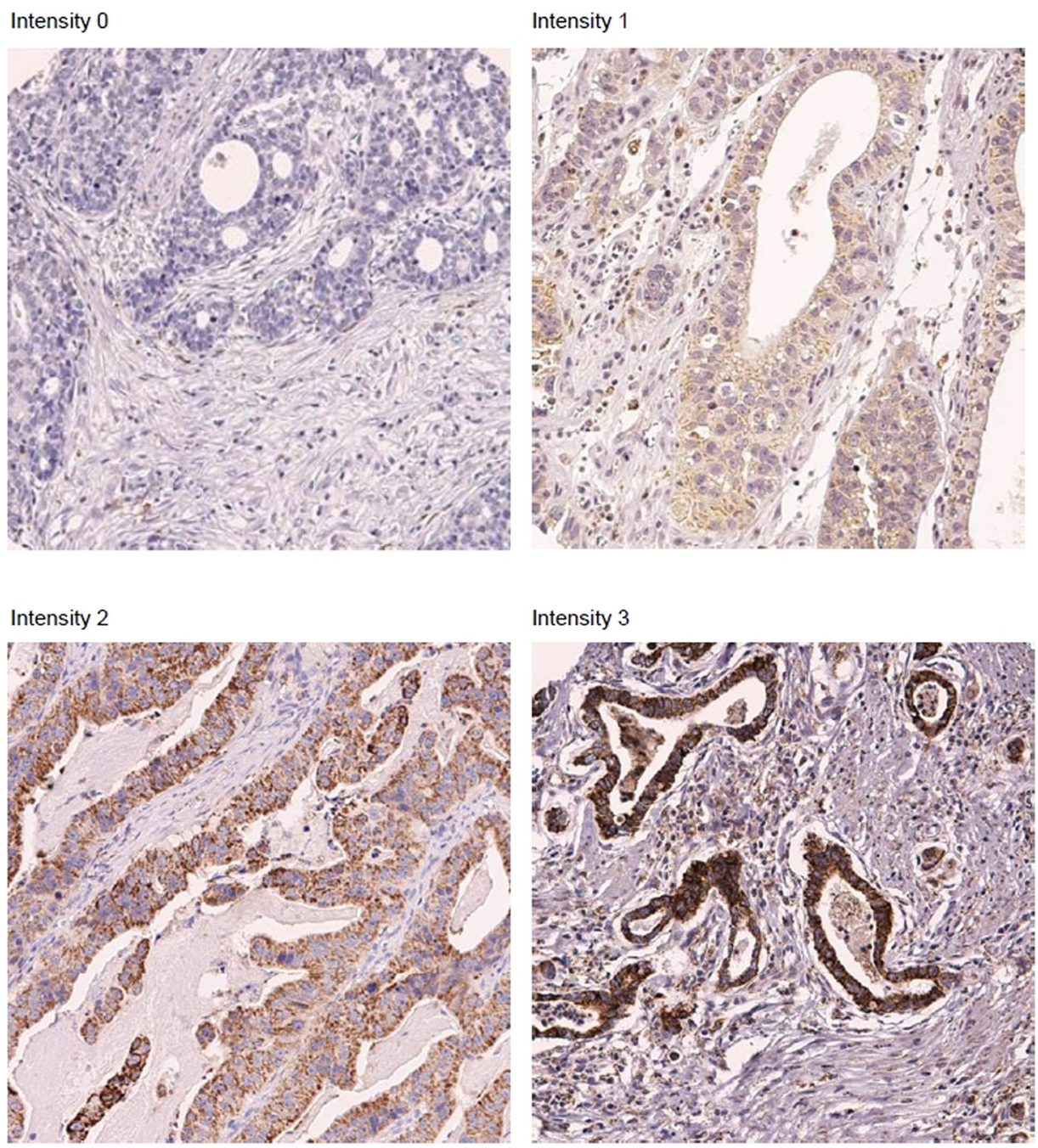

Figure 2: Representative sections showing MerTK overexpression on immunohistochemical studies. $(\times 200)$.

seems to be the major pathogenesis in various neoplasms $[10,12-14,31]$. Gas6, the ligand of TAM RTK family, is also known to act as a tumor mitogen [32]. In several animal studies, it was suggested that TAM RTKs could be an oncogenic driver $[33,34]$. On the other hands, several recent studies have shown that TAM RTKs rather act as a manner of "non-oncogene addiction", that is, providing favorable stimuli on tumor survival under stressful conditions which causes chemoresistance [12, $15,31]$ or promoting tumor metastasis by suppressing natural killer (NK) cell function $[35,36]$. Our findings that the growth of MerTK positive GC cells was profoundly inhibited by either MerTK-specific shRNAs or a small molecular inhibitor suggest that MerTK positive GC cells might depend on MerTK for their survival. It is also consistent with previous studies that MerTK specific inhibition resulted in increased incidence of cellular apoptosis.

Unlike other solid tumors, the prognostic role of MerTK has not been extensively studied in GC. Its expression was first identified in several GC cell lines in 1998 [37]. After that, only one published report has shown that the co-expression of MerTK and Axl was associated with adverse outcomes in a series of $96 \mathrm{GC}$ patients [38]. Our experimental results are consistent with this finding. Among our IHC validation cohort consisting of $192 \mathrm{GC}$ patients treated with curative surgery followed by adjuvant chemoradiation, 16 patients $(8.3 \%)$ had tumors with increased MerTK signal by IHC, and they had significantly short OS. And this result is comparable to those of the MerTK mRNA overexpressing population identified by the Nanostring assay (4 of 54, 7.4\%). Moreover, those who had MerTK overexpressed GC demonstrated unique clinicopathologic features, that is, they were more frequently associated with an intestinaltype cancer and an advanced stage. Multivariate analysis revealed that MerTK protein expression was associated with poor OS, along with other known prognostic factors, including an advanced stage and a diffuse-type cancer, by Lauren's classification. 


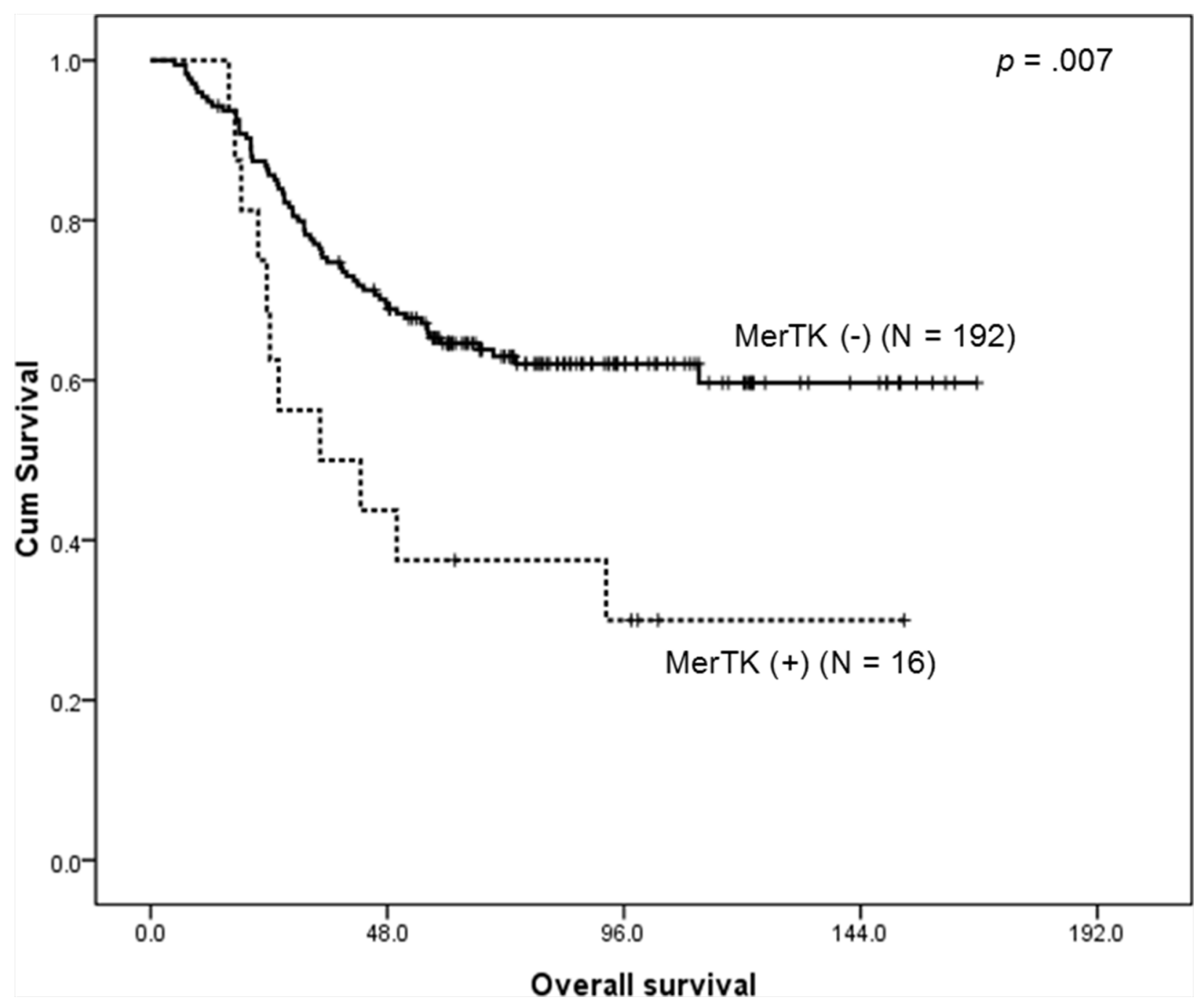

Figure 3: Kaplan-Meier survival curve for overall survival according to the MerTK status demonstrates that patients with MerTK overexpressing tumors have a worse outcome.

In terms of MerTK immunohistochemical analysis in $\mathrm{GC}$ patients, there are no validated criteria. In $\mathrm{Wu}$ et al.'s report [38], if positive stained cells are more than $25 \%$ of all tumor cells, it was interpreted as positive protein expression. With this criterion, 60 out of 96 cases $(62.5 \%)$ were regarded as MerTK expressing tumors, which looks somewhat high in rate. In the current study, however, we used both intensity scale and proportion scale. The criteria for positive stain were 2 or 3 in intensity and positive stains in more than 2 out of 4 tissue cores. Moreover, as we validated the criteria through clinicopathologic characterization and survival analysis, this could be used in the future analysis for MerTK in GC patients.

Diverse downstream signals of MerTK have been identified, including MAPK/ERK, AKT, and PLC $\gamma$ pathways [39-42] which differ according to cell type and tissue microenvironment [43]. In gastric cancer, there is one report that administration of recombinant Gas6 phosphorylated Axl in GC cell lines, and then enhanced cellular survival and suppressed apoptosis via Akt pathway [44]. In agreement with this report, we found that both phospho-ERK and phospho-AKT were significantly reduced by MerTK inhibition, suggesting that they are downstream signaling pathways in gastric cancer cells.

Owing to the recent discovery of the significance of TAM RTKs, several TAM-specific inhibitors are currently in development [10,45-48], and in the current analysis, we used UNC1062. UNC1062 is a potent and selective MerTK inhibitor with minimal effects on potassium channel, which could cause long QT syndrome [24]. In a study dealing with the MerTK $(+)$ melanoma cells [11], UNC1062 induced cell death similar to the current study, and it also inhibited migration and invasion of the melanoma cells. In pharmacologic point of views, this agent has demonstrated a potent anti-MerTK effect, particularly in a human leukemia cell line (IC50 of 1.1 $\mathrm{nM}$ ), and a somewhat lower effect in human solid cancer cell lines (around $300 \mathrm{nM}$ ) [24]. The IC50 values from 
TABLE 2: Clinicopathological characteristics of MerTK(+) GC patients and the multivariate analysis for overall survival

\begin{tabular}{|c|c|c|c|}
\hline \multicolumn{4}{|c|}{ Clinicopathologic features of MerTK(+) GC patients } \\
\hline & $\begin{array}{l}\text { MerTK positive } \\
\qquad(N=16)\end{array}$ & $\begin{array}{l}\text { MerTK negative } \\
\qquad(N=176)\end{array}$ & $p$ \\
\hline Age, $<=60$ & $11(68.8 \%)$ & $127(72.2 \%)$ & 0.716 \\
\hline Male & $14(87.5 \%)$ & $106(60.2 \%)$ & 0.059 \\
\hline \multicolumn{4}{|l|}{ Lauren's classification } \\
\hline Intestinal-type & $13(81.3 \%)$ & $49(27.8 \%)$ & $<0.0001$ \\
\hline Diffuse-type & $3(18.8 \%)$ & $120(68.2 \%)$ & \\
\hline Others & $0(0.0)$ & $7(4.0 \%)$ & \\
\hline \multicolumn{4}{|l|}{ Stage } \\
\hline Stage $\mathrm{Ib} / \mathrm{II}$ & $5(31.3 \%)$ & $103(58.5 \%)$ & 0.036 \\
\hline Stage III/IV & $11(68.8 \%)$ & $73(41.5 \%)$ & \\
\hline Lymphovascular invasion $(+)$ & $7(43.8 \%)$ & $85(48.3 \%)$ & 0.072 \\
\hline \multicolumn{4}{|c|}{ Multivariate analysis for overall survival } \\
\hline & HR & $95 \% \mathrm{CI}$ & $p$ \\
\hline Advanced stage (III/IV) & 2.79 & $1.61-4.85$ & $<0.001$ \\
\hline Diffuse-type cancer & 2.29 & $1.16-4.50$ & 0.017 \\
\hline MerTK overexpression & $\mathbf{5 . 5 0}$ & $2.41-12.59$ & $<0.001$ \\
\hline Male & 1.025 & $0.57-1.83$ & 0.934 \\
\hline Lymphovascular invasion & 1.48 & $0.84-2.61$ & 0.176 \\
\hline
\end{tabular}

our analyses on GC cell lines and PDCs were $0.21 \mu \mathrm{M}$ and $0.14 \mu \mathrm{M}$, respectively. Although the levels are slightly higher than that of the leukemia cell line, treatment with $1.0 \mu \mathrm{M}$ UNC1062 was sufficient to completely abrogate colony formation of GC cell lines and PDCs. While several approved agents including bosutinib, crizotinib and vandetinib also contain anti-TAM RTK efficacies [46], the effects of TAM-directed therapy have yet been evaluated in the clinical setting. Further analysis of their therapeutic roles is required.

The present study has several limitations. Regarding the retrospective analysis, patients with metastatic disease were not included. If MerTK is associated with tumor survival and metastasis, patients with metastatic disease may show more frequent MerTK expression. And as with study by $\mathrm{Wu}$ et al. [38], only Asian patients were included which warrants further analysis in the Western population. And as MerTK is known to be involved chemoresistance, additional analyses regarding the combined treatment are required.

To our knowledge, the current study provided with useful information to define prognostic and functional roles of MerTK in GC for the first time. The unique features of MerTK (+) GC patients could provide with further characterization of GC population, and it might be a potential therapeutic target as well. The analysis for role of MerTK inhibitors, including UNC1062, in GC patients should be continued including prospective clinical trials.

\section{MATERIALS AND METHODS}

\section{Establishing PDCs, cell culture, and reagents}

To establish PDCs from metastatic GC patients with malignant effusion, those who were enrolled onto the SMC Oncology Biomarker study (NCT\#01831609) were screened for the MerTK overexpression by Western blot. All patients provided informed consent form according to the SMC Institutional Review Board. Briefly, collected effusions (1-5 L) were divided into $50 \mathrm{~mL}$ tubes, centrifuged at $1500 \mathrm{rpm}$ for $10 \mathrm{~min}$, and washed twice with PBS. Either PDCs or commercial GC cell lines, which were purchased from the Korea Cell Line Bank (KCLB, Seoul, Korea), all cells were grown in RPMI-1640 medium (PAA Laboratories GmbH, Austria) supplemented with $10 \%$ heat-inactivated fetal bovine serum, an antibiotic, and an antimycotic. Cells were incubated at $37^{\circ} \mathrm{C}$ in $5 \% \mathrm{CO}_{2}$ and the medium changed twice a week. After becoming confluent, cells were subdivided into new flasks until the end of the experiment. 


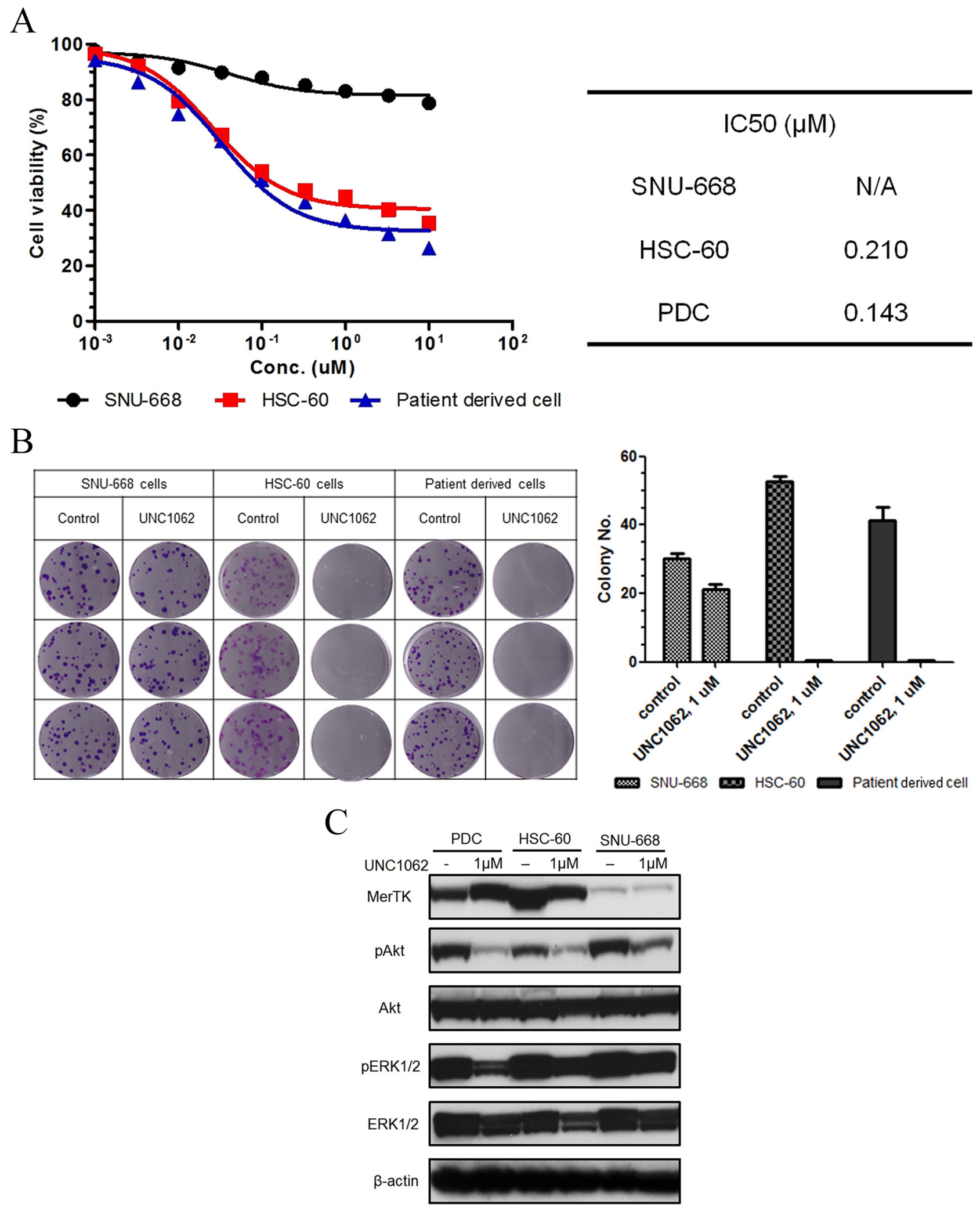

Figure 4: A. Results of the MTS assay for a MerTK-specific inhibitor (UNC1062). Both HSC-60 and MerTK-positive patient-derived cells (PDCs) had similar sensitivities and IC50 values. The cellular viability of SNU-668 was not affected by UNC1062. B. The colony formation of HSC-60 and MerTK-positive PDCs was completely abolished by UNC1062, but SNU-668 was unaffected. C. When cells were treated with UNC1062, phosphorylation of AKT and ERK1/2 were decreased in HSC-60 and MerTK positive PDCs, suggesting they are downstream output pathways of MerTK. 


\section{Western blot analysis}

Total cell extracts were obtained using a lysis buffer (20 mM HEPES pH 7.4, $150 \mathrm{mM} \mathrm{NaCl}, 1 \mathrm{mM}$ $\mathrm{MgCl}_{2}, 1 \mathrm{mM}$ EDTA, $2 \mathrm{mM}$ EGTA, 10\% glycerol, $1 \%$ Triton X-100, $1 \mu \mathrm{g} / \mathrm{mL}$ leupeptin, and $1 \mu \mathrm{g} / \mathrm{mL}$ aprotinin). Equal amounts (40 $\mu \mathrm{g})$ of cell lysates were resolved on $8 \%$ or $12 \%$ Bis-Tris gels with MOPS running buffer (Invitrogen, Novex), transferred to PVDF membranes, and incubated with specific antibodies against MerTK (Abcamplc, Cambridge, UK) and betaActin (Santa Cruz Biotechnology, Santa Cruz, CA, USA). Immune complexes were visualized as enhanced chemiluminescence (Novex ECL, Invitrogen).

\section{RT-PCR}

cDNA were generated by reverse-transcription of purified RNA, using the Omniscript RT kit (Qiagen, Hilden, Germany) following the manufacturer's protocol $\left(60\right.$ min reaction at $37^{\circ} \mathrm{C}$ ). The MerTK forward primer sequence was 5'-CGAGCTCGGATCTCTGTTCA-3', and the reverse primer sequence was 5'-GAGGGGGCATAATCTACCCA-3', which resulted in a 269-bp amplicon. A 300-bp amplicon of ACTB was generated as a positive control; the sequence of the forward primer was 5'-TCATCACCATTGGCAAT GAG-3', and the sequence of the reverse primer was 5'-CACTGTGTTGGCGTACAGGT-3'. The PCR profile was 35 cycles of $95^{\circ} \mathrm{C}$ for $1 \mathrm{~min}, 54^{\circ} \mathrm{C}$ for $1 \mathrm{~min}$, and $72^{\circ} \mathrm{C}$ for $1 \mathrm{~min}$, with a final extension of $10 \mathrm{~min}$ at $72^{\circ} \mathrm{C}$.

\section{Lentivirus production and transduction}

MerTK targeting small hairpin RNA (shRNA) and control shGFP were obtained from Sigma Mission shRNA (3 different constructs). VSV-G pseudotyped lentiviruses were produced by co-transfecting 293T cells with the transfer vector and 3 packaging vectors (pMDLg/pRRE, pRSV-REV, and pCMV-VSVG), and the resultant virions were purified by ultracentrifugation. We plated $1 \times 10^{4}$ of HSC-60 or SNU-668 cells in 6-well plates and transduced them with lentivirus, using $8 \mathrm{~g} / \mathrm{mL}$ polybrene (Sigma).

\section{Cell growth curve and cycle analysis}

We examined the effect of MerTK knockdown on cell growth in HSC-60 and SNU-668 cells. At 72 h post-shRNA transduction, we seeded, in triplicate, samples of cells in $\log$ phase growth at a density of $1 \times 10^{4}$ cells/well in 6-well plates. The cells were counted, pelleted by centrifugation at $1300 \mathrm{rpm}$ for $3 \mathrm{~min}$, and re-suspended in fresh media. We counted triplicate sets of cells after $12 \mathrm{~d}$ and calculated the mean cell number for each condition. From these data, we derived the growth curves.
Regarding the cell cycle analysis, cultured cells were removed with trypsin and fixed with $70 \%$ ethanol at $4{ }^{\circ} \mathrm{C}$ overnight. Subsequently, they were stained with propidium iodide $(20 \mu \mathrm{g} / \mathrm{mL}$ propidium iodide, 200 $\mu \mathrm{g} / \mathrm{mL}$ DNase-free RNase A, and $0.1 \%$ Triton X-100, prepared freshly in PBS). The cellular DNA complement was analyzed using the FACS Calibur (Becton Dickinson, San Jose, CA). Data were analyzed using the CellQuest software (Becton Dickinson).

\section{Patients for immunohistochemical study}

Among the GC patients who had undergone surgery at Samsung Medical Center from July 1995 to December 2005, 192 were selected based on the following criteria: age $\geq 18$ years; pathologically confirmed GC; complete surgical resection of tumor with curative intent; and the availability of formalin-fixed paraffin-embedded tissue suitable for immunohistochemical (IHC) analysis. All patients had undergone gastrectomy with extensive (D2) lymph node dissection, and the treatment was completed by administering 2 more cycles of 5-fluorouracil/ leucovorin-based chemoradiation. The pathologic stages were evaluated according to the 6th edition of the staging system published by the American Joint Committee on Cancer (AJCC).

\section{Tissue microarray construction and IHC stains}

Tissue microarrays were constructed using a Beecher Manual Tissue Microarrayer (MTA-1, Beecher Instruments Inc., Wisconsin, USA). All available H\&Estained slides were reviewed, and 4 representative tumor regions were taken from donor formalin-fixed paraffin-embedded blocks using a 0.6-mm core punch, and arrayed into recipient blocks. IHC studies were performed with 4- $\mu \mathrm{m}$-thick tissue microarray sections by using rabbit anti-MERTK antibody (HPA036196, Sigma Life Science, MO, USA). Tissue microarray sections were deparaffinized 3 times in xylene for a total of $15 \mathrm{~min}$ and subsequently rehydrated. Immunostaining was performed using a Bond-max autoimmunostainer (Leica Biosystems, Melbourne, Australia) with Bond ${ }^{\mathrm{TM}}$ Polymer refine detection, DS9800 (Vision Biosystems, Melbourne, Australia). Briefly, antigen retrieval was achieved by heating samples to $97^{\circ} \mathrm{C}$ for $20 \mathrm{~min}$ in ER1 buffer, blocking endogenous peroxidase activity with $3 \%$ hydrogen peroxidase for $5 \mathrm{~min}$, and incubating samples with a 1:50 dilution of primary antibody for $15 \mathrm{~min}$ at room temperature.

Positive signal for MerTK manifested as cytoplasmic or membranous reactivity. The staining intensity was graded on a scale of 0 to 3 , where 0 is negative, 1 is weak (only visible at high magnification using a $20 \times$ objective), 2 is moderate (readily visible 
at low magnification, $4 \times$ objective), and 3 is strong (strikingly positive, even at low power magnification). When moderate-to-strong reactivity was observed in more than 2 of the 4 cores of tumor cells, it was scored as positive staining. Negative controls (substitution of PBS for the primary antibody) were run simultaneously. The slides were assessed by a pathologist (IG. D.), blinded to the clinical outcome.

\section{Drug treatment and cellular growth analyses}

Cells $\left(3 \times 10^{3}\right.$ in $100 \mu 1 /$ well $)$ were seeded on 96-well plates and incubated for $24 \mathrm{~h}$ at $37^{\circ} \mathrm{C}$ and treated with for 3 days UNC1062 at $37^{\circ} \mathrm{C}$. After drug treatment, MTS solution was added to each well and incubation was continued for $4 \mathrm{~h}$ at $37^{\circ} \mathrm{C}$. The absorbance value of each well was measured with a microplate reader set at $490 \mathrm{~nm}$. All experiments were performed in triplicate. UNC1062 inhibitor was kindly provided by Wang et al. [24].

Regarding the colony forming assay, about $2 \times 10^{2}$ cells per well were added to a 6 -well culture plate, using three wells for each group. After incubation at $37^{\circ} \mathrm{C}$ for $14 \mathrm{~d}$, the cells were washed twice with PBS and stained with $0.5 \%$ crystal violet in $20 \%$ methanol. The number of colonies was counted under a microscope.

\section{Statistical analysis}

The primary end-point for MerTK-IHC analysis was overall survival (OS), defined as the time from surgery to the date of death or the last follow-up, and it was calculated using Kaplan-Meier method. The $\chi^{2}$ test or Fisher exact test was used to determine the strength of associations between MerTK protein expression and different clinicopathological factors. The Cox proportional hazard (backward linear regression) model was used to evaluate the associations between clinicopathological factors and OS. All tests were two-tailed, and P values $<0.05$ were considered significant. Statistical analysis was performed using SPSS 20 software for Windows (SPSS Inc., Chicago, IL).

\section{ACKNOWLEDGMENTS}

This work was supported by a grant from the Korean Health Technology R\&D Project, Ministry of Health \& Welfare, Republic of Korea (HI14C2188). Support was also provided by a grant from the 20 by 20 project of Samsung Medical Center (GF01140111).

\section{COMPETING INTERESTS}

The authors have declared no competing interests.

\section{REFERENCES}

1. Cunningham D, Jost LM, Purkalne G, Oliveira J, Force EGT. ESMO Minimum Clinical Recommendations for diagnosis, treatment and follow-up of gastric cancer. Annals of oncology. 2005; 16:i22-23.

2. Dicken BJ, Bigam DL, Cass C, Mackey JR, Joy AA, Hamilton SM. Gastric adenocarcinoma: review and considerations for future directions. Annals of surgery. 2005; 241:27-39.

3. Noh SH, Park SR, Yang HK, Chung HC, Chung IJ, Kim SW, Kim HH, Choi JH, Kim HK, Yu W, Lee JI, Shin DB, Ji J, et al. Adjuvant capecitabine plus oxaliplatin for gastric cancer after D2 gastrectomy (CLASSIC): 5-year follow-up of an open-label, randomised phase 3 trial. The Lancet Oncology. 2014; 15:1389-1396.

4. Wagner AD, Unverzagt S, Grothe W, Kleber G, Grothey A, Haerting J, Fleig WE. Chemotherapy for advanced gastric cancer. The Cochrane database of systematic reviews. 2010; CD004064.

5. Al-Batran SE, Hartmann JT, Probst S, Schmalenberg H, Hollerbach S, Hofheinz R, Rethwisch V, Seipelt G, Homann N, Wilhelm G, Schuch G, Stoehlmacher J, Derigs HG, et al. Phase III trial in metastatic gastroesophageal adenocarcinoma with fluorouracil, leucovorin plus either oxaliplatin or cisplatin: a study of the Arbeitsgemeinschaft Internistische Onkologie. Journal of clinical oncology: official journal of the American Society of Clinical Oncology. 2008; 26:1435-1442.

6. Van Cutsem E, Moiseyenko VM, Tjulandin S, Majlis A, Constenla M, Boni C, Rodrigues A, Fodor M, Chao Y, Voznyi E, Risse ML, Ajani JA. Phase III study of docetaxel and cisplatin plus fluorouracil compared with cisplatin and fluorouracil as first-line therapy for advanced gastric cancer: a report of the V325 Study Group. Journal of clinical oncology: official journal of the American Society of Clinical Oncology. 2006; 24:4991-4997.

7. Bang YJ, Van Cutsem E, Feyereislova A, Chung HC, Shen L, Sawaki A, Lordick F, Ohtsu A, Omuro Y, Satoh T, Aprile G, Kulikov E, Hill J, et al. Trastuzumab in combination with chemotherapy versus chemotherapy alone for treatment of HER2-positive advanced gastric or gastrooesophageal junction cancer (ToGA): a phase 3, open-label, randomised controlled trial. Lancet. 2010; 376:687-697.

8. Fuchs CS, Tomasek J, Yong CJ, Dumitru F, Passalacqua R, Goswami C, Safran H, dos Santos LV, Aprile G, Ferry DR, Melichar B, Tehfe M, Topuzov E, et al. Ramucirumab monotherapy for previously treated advanced gastric or gastro-oesophageal junction adenocarcinoma (REGARD): an international, randomised, multicentre, placebo-controlled, phase 3 trial. Lancet. 2014; 383:31-39.

9. Wilke H, Muro K, Van Cutsem E, Oh SC, Bodoky G, Shimada Y, Hironaka S, Sugimoto N, Lipatov O, Kim TY, Cunningham D, Rougier P, Komatsu Y, et al. Ramucirumab plus paclitaxel versus placebo plus paclitaxel in patients 
with previously treated advanced gastric or gastro-oesophageal junction adenocarcinoma (RAINBOW): a doubleblind, randomised phase 3 trial. The lancet oncology. 2014; 15:1224-1235.

10. Tworkoski KA, Platt JT, Bacchiocchi A, Bosenberg M, Boggon TJ, Stern DF. MERTK controls melanoma cell migration and survival and differentially regulates cell behavior relative to AXL. Pigment cell \& melanoma research. 2013; 26:527-541.

11. Schlegel J, Sambade MJ, Sather S, Moschos SJ, Tan AC, Winges A, DeRyckere D, Carson CC, Trembath DG, Tentler JJ, Eckhardt SG, Kuan PF, Hamilton RL, et al. MERTK receptor tyrosine kinase is a therapeutic target in melanoma. The Journal of clinical investigation. 2013; 123:2257-2267.

12. Lee-Sherick AB, Eisenman KM, Sather S, McGranahan A, Armistead PM, McGary CS, Hunsucker SA, Schlegel J, Martinson H, Cannon C, Keating AK, Earp HS, Liang X, et al. Aberrant Mer receptor tyrosine kinase expression contributes to leukemogenesis in acute myeloid leukemia. Oncogene. 2013; 32:5359-5368.

13. Graham DK, Salzberg DB, Kurtzberg J, Sather S, Matsushima GK, Keating AK, Liang X, Lovell MA, Williams SA, Dawson TL, Schell MJ, Anwar AA, Snodgrass HR, Earp HS. Ectopic expression of the proto-oncogene Mer in pediatric T-cell acute lymphoblastic leukemia. Clinical cancer research: an official journal of the American Association for Cancer Research. 2006; 12:2662-2669.

14. Ek S, Hogerkorp CM, Dictor M, Ehinger M, Borrebaeck CA. Mantle cell lymphomas express a distinct genetic signature affecting lymphocyte trafficking and growth regulation as compared with subpopulations of normal human B cells. Cancer research. 2002; 62:4398-4405.

15. Keating AK, Kim GK, Jones AE, Donson AM, Ware K, Mulcahy JM, Salzberg DB, Foreman NK, Liang X, Thorburn A, Graham DK. Inhibition of Mer and Axl receptor tyrosine kinases in astrocytoma cells leads to increased apoptosis and improved chemosensitivity. Molecular cancer therapeutics. 2010; 9:1298-1307.

16. Knubel KH, Pernu BM, Sufit A, Nelson S, Pierce AM, Keating AK. MerTK inhibition is a novel therapeutic approach for glioblastoma multiforme. Oncotarget. 2014; 5:1338-1351. doi: 10.18632/oncotarget.1793.

17. Scott RS, McMahon EJ, Pop SM, Reap EA, Caricchio R, Cohen PL, Earp HS, Matsushima GK. Phagocytosis and clearance of apoptotic cells is mediated by MER. Nature. 2001; 411:207-211.

18. Holland SJ, Powell MJ, Franci C, Chan EW, Friera AM, Atchison RE, McLaughlin J, Swift SE, Pali ES, Yam G, Wong S, Lasaga J, Shen MR, et al. Multiple roles for the receptor tyrosine kinase axl in tumor formation. Cancer research. 2005; 65:9294-9303.

19. Prieto AL, Weber JL, Lai C. Expression of the receptor protein-tyrosine kinases Tyro-3, Axl, and mer in the developing rat central nervous system. The Journal of comparative neurology. 2000; 425:295-314.
20. Verma A, Warner SL, Vankayalapati H, Bearss DJ, Sharma S. Targeting Axl and Mer kinases in cancer. Molecular cancer therapeutics. 2011; 10:1763-1773.

21. Hutterer M, Knyazev P, Abate A, Reschke M, Maier H, Stefanova N, Knyazeva T, Barbieri V, Reindl M, Muigg A, Kostron H, Stockhammer G, Ullrich A. Axl and growth arrest-specific gene 6 are frequently overexpressed in human gliomas and predict poor prognosis in patients with glioblastoma multiforme. Clinical cancer research: an official journal of the American Association for Cancer Research. 2008; 14:130-138.

22. Koorstra JB, Karikari CA, Feldmann G, Bisht S, Rojas PL, Offerhaus GJ, Alvarez H, Maitra A. The Axl receptor tyrosine kinase confers an adverse prognostic influence in pancreatic cancer and represents a new therapeutic target. Cancer biology \& therapy. 2009; 8:618-626.

23. Gjerdrum C, Tiron C, Hoiby T, Stefansson I, Haugen H, Sandal T, Collett K, Li S, McCormack E, Gjertsen BT, Micklem DR, Akslen LA, Glackin C, Lorens JB. Axl is an essential epithelial-to-mesenchymal transition-induced regulator of breast cancer metastasis and patient survival. Proceedings of the National Academy of Sciences of the United States of America. 2010; 107:1124-1129.

24. Liu J, Zhang W, Stashko MA, Deryckere D, Cummings CT, Hunter D, Yang C, Jayakody CN, Cheng N, Simpson C, Norris-Drouin J, Sather S, Kireev D, et al. UNC1062, a new and potent Mer inhibitor. European journal of medicinal chemistry. 2013; 65:83-93.

25. Park SH, Sohn TS, Lee J, Lim DH, Hong ME, Kim KM, Sohn I, Jung SH, Choi MG, Lee JH, Bae JM, Kim S, Kim ST, et al. Phase III Trial to Compare Adjuvant Chemotherapy With Capecitabine and Cisplatin Versus Concurrent Chemoradiotherapy in Gastric Cancer: Final Report of the Adjuvant Chemoradiotherapy in Stomach Tumors Trial, Including Survival and Subset Analyses. Journal of clinical oncology: official journal of the American Society of Clinical Oncology. 2015.

26. Wang K, Kan J, Yuen ST, Shi ST, Chu KM, Law S, Chan TL, Kan Z, Chan AS, Tsui WY, Lee SP, Ho SL, Chan $\mathrm{AK}$, et al. Exome sequencing identifies frequent mutation of ARID1A in molecular subtypes of gastric cancer. Nature genetics. 2011; 43:1219-1223.

27. Zang ZJ, Cutcutache I, Poon SL, Zhang SL, McPherson JR, Tao J, Rajasegaran V, Heng HL, Deng N, Gan A, Lim KH, Ong CK, Huang D, et al. Exome sequencing of gastric adenocarcinoma identifies recurrent somatic mutations in cell adhesion and chromatin remodeling genes. Nature genetics. 2012; 44:570-574.

28. Deng N, Goh LK, Wang H, Das K, Tao J, Tan IB, Zhang S, Lee M, Wu J, Lim KH, Lei Z, Goh G, Lim QY, et al. A comprehensive survey of genomic alterations in gastric cancer reveals systematic patterns of molecular exclusivity and co-occurrence among distinct therapeutic targets. Gut. 2012; 61:673-684. 
29. Graham DK, Dawson TL, Mullaney DL, Snodgrass HR, Earp HS. Cloning and mRNA expression analysis of a novel human protooncogene, c-mer. Cell growth \& differentiation: the molecular biology journal of the American Association for Cancer Research. 1994; 5:647-657.

30. Greenman C, Stephens P, Smith R, Dalgliesh GL, Hunter C, Bignell G, Davies H, Teague J, Butler A, Stevens C, Edkins S, O'Meara S, Vastrik I, et al. Patterns of somatic mutation in human cancer genomes. Nature. 2007; 446:153-158.

31. Linger RM, Cohen RA, Cummings CT, Sather S, MigdallWilson J, Middleton DH, Lu X, Baron AE, Franklin WA, Merrick DT, Jedlicka P, DeRyckere D, Heasley LE, Graham DK. Mer or Axl receptor tyrosine kinase inhibition promotes apoptosis, blocks growth and enhances chemosensitivity of human non-small cell lung cancer. Oncogene. 2013 ; 32:3420-3431.

32. Loges S, Schmidt T, Tjwa M, van Geyte K, Lievens D, Lutgens E, Vanhoutte D, Borgel D, Plaisance S, Hoylaerts M, Luttun A, Dewerchin M, Jonckx B, Carmeliet P. Malignant cells fuel tumor growth by educating infiltrating leukocytes to produce the mitogen Gas6. Blood. 2010; 115:2264-2273.

33. Jia R, Mayer BJ, Hanafusa T, Hanafusa H. A novel oncogene, $v$-ryk, encoding a truncated receptor tyrosine kinase is transduced into the RPL30 virus without loss of viral sequences. Journal of virology. 1992; 66:5975-5987.

34. Keating AK, Salzberg DB, Sather S, Liang X, Nickoloff S, Anwar A, Deryckere D, Hill K, Joung D, Sawczyn KK, Park J, Curran-Everett D, McGavran L, et al. Lymphoblastic leukemia/lymphoma in mice overexpressing the Mer (MerTK) receptor tyrosine kinase. Oncogene. 2006; 25:6092-6100.

35. Paolino M, Choidas A, Wallner S, Pranjic B, Uribesalgo I, Loeser S, Jamieson AM, Langdon WY, Ikeda F, Fededa JP, Cronin SJ, Nitsch R, Schultz-Fademrecht C, et al. The E3 ligase $\mathrm{Cbl}-\mathrm{b}$ and TAM receptors regulate cancer metastasis via natural killer cells. Nature. 2014; 507:508-512.

36. Cook RS, Jacobsen KM, Wofford AM, DeRyckere D, Stanford J, Prieto AL, Redente E, Sandahl M, Hunter DM, Strunk KE, Graham DK, Earp HS 3rd. MerTK inhibition in tumor leukocytes decreases tumor growth and metastasis. The Journal of clinical investigation. 2013; 123:3231-3242.

37. Lin JS, Lu CW, Huang CJ, Wu PF, Robinson D, Kung HJ, Chi CW, Wu CW, Yang WK, Whang-Peng JJ, Lin WC. Protein-tyrosine kinase and protein-serine/threonine kinase expression in human gastric cancer cell lines. Journal of biomedical science. 1998; 5:101-110.

38. Wu CW, Li AF, Chi CW, Lai CH, Huang CL, Lo SS, Lui WY, Lin WC. Clinical significance of AXL kinase family in gastric cancer. Anticancer research. 2002; 22:1071-1078.

39. Ling L, Kung HJ. Mitogenic signals and transforming potential of Nyk, a newly identified neural cell adhesion molecule-related receptor tyrosine kinase. Molecular and cellular biology. 1995; 15:6582-6592.

40. Chen J, Carey K, Godowski PJ. Identification of Gas6 as a ligand for Mer, a neural cell adhesion molecule related receptor tyrosine kinase implicated in cellular transformation. Oncogene. 1997; 14:2033-2039.

41. Todt JC, Hu B, Curtis JL. The receptor tyrosine kinase MerTK activates phospholipase $\mathrm{C}$ gamma2 during recognition of apoptotic thymocytes by murine macrophages. Journal of leukocyte biology. 2004; 75:705-713.

42. Sen $\mathrm{P}$, Wallet MA, Yi Z, Huang $Y$, Henderson $M$, Mathews CE, Earp HS, Matsushima G, Baldwin AS Jr., Tisch RM. Apoptotic cells induce Mer tyrosine kinasedependent blockade of NF-kappaB activation in dendritic cells. Blood. 2007; 109:653-660.

43. Linger RM, Keating AK, Earp HS, Graham DK. TAM receptor tyrosine kinases: biologic functions, signaling, and potential therapeutic targeting in human cancer. Advances in cancer research. 2008; 100:35-83.

44. Sawabu T, Seno H, Kawashima T, Fukuda A, Uenoyama Y, Kawada M, Kanda N, Sekikawa A, Fukui H, Yanagita M, Yoshibayashi H, Satoh S, Sakai Y, et al. Growth arrest-specific gene 6 and Axl signaling enhances gastric cancer cell survival via Akt pathway. Molecular carcinogenesis. 2007; 46:155-164.

45. Zhang W, DeRyckere D, Hunter D, Liu J, Stashko MA, Minson KA, Cummings CT, Lee M, Glaros TG, Newton DL, Sather S, Zhang D, Kireev D, et al. UNC2025, a potent and orally bioavailable MER/FLT3 dual inhibitor. Journal of medicinal chemistry. 2014; 57:7031-7041.

46. Davis MI, Hunt JP, Herrgard S, Ciceri P, Wodicka LM, Pallares G, Hocker M, Treiber DK, Zarrinkar PP. Comprehensive analysis of kinase inhibitor selectivity. Nature biotechnology. 2011; 29:1046-1051.

47. Burbridge MF, Bossard CJ, Saunier C, Fejes I, Bruno A, Leonce S, Ferry G, Da Violante G, Bouzom F, Cattan V, Jacquet-Bescond A, Comoglio PM, Lockhart BP, et al. S49076 is a novel kinase inhibitor of MET, AXL, and FGFR with strong preclinical activity alone and in association with bevacizumab. Molecular cancer therapeutics. 2013; 12:1749-1762.

48. Mollard A, Warner SL, Call LT, Wade ML, Bearss JJ, Verma A, Sharma S, Vankayalapati H, Bearss DJ. Design, Synthesis and Biological Evaluation of a Series of Novel Axl Kinase Inhibitors. ACS medicinal chemistry letters. 2011; 2:907-912. 